\title{
INVESTIGATION INTO TECHNOLOGICAL PARAMETERS OF BITUMEN BATCHING IN AN ASPHALT MIXING PLANT
}

\author{
Justas BRAŽIŪNAS \\ Department of Transport Technological Equipment, Vilnius Gediminas Technical University, \\ Plytinès g. 27, LT-10105 Vilnius, Lithuania
}

Received 19 Jan 2015; accepted 13 Apr 2015

\begin{abstract}
An appropriate bitumen content and its properties in hot mix asphalt (HMA) mixture impact on the long-term mechanical strength of the laid asphalt pavement and the required road operation properties. During the production of a HMA mixture in an asphalt mixing plant (AMP), relationships between the structure and interaction of the mixture are established based on technological processes that specify bitumen batching and component mixing. These processes ensure the long-term strength, texture, evenness, the degree of damage and rheological properties of road pavement. The presented mathematical model enables us to determine the distribution of oxygen pressure by time in differently sized drops of bitumen during their fall into a mixer. The model considers oxygen diffusion, which depends on temperature, and heat conductivity, which depends on temperature, density and specific heat. An active experimental investigation under real production conditions demonstrated that the method of bitumen discharge from a batcher, temperature and time spent mixing materials with hot mineral aggregates impact on properties of bitumen binder within the produced HMA mixture. Parameters of technological processes for mixing of bitumen with mineral aggregates that occur in a bitumen batching system (BBS) are stochastic and impact on the composition of bitumen binder as well as physical and mechanical properties of the produced HMA mixture, namely, air void content, stability, flow and Marshall quotient.
\end{abstract}

Keywords: bitumen, hot mix asphalt (HMA), stone mastic asphalt (SMA), bitumen batching system (BBS), job-mix formula (JMF), oxidation, short-term ageing, rheology, penetration, viscosity, asphalt mixing plant (AMP), carbonyl formation.

\section{Introduction}

As road surface is exposed to destructive climate and weather factors as well as heavy vehicle loads, it wears and deflects. In recent decades, the growing problem of deepening ruts has been added to cracks and potholes (Sivilevičius, Vansauskas 2013; Judycki 2010). In asphalt concrete, bitumen binds together the material made of mineral particles into a strong conglomerate that has a complicated structure. It becomes capable of withstanding the destructive effect of vehicles and other negative factors. The optimal amount of bitumen, which is determined by calculation and laboratory testing, should be maintained in mix batches of hot-mix asphalt (HMA) obtained from a mixer of an asphalt mixing plant (AMP). The mass of weighted binder in the batcher tank of a periodical type AMP must be such that its percentage in all mix batches of HMA mix lot would correspond to the designed amount indicated in the job-mix formula (JMF). The first significant technological parameter of a bitumen batching system (BBS) is percent deviation of discharged bitumen batches from the value set in the project, i.e. the JMF. Insufficient content of bitumen fails to coat all min- eral aggregate particles with the film of required thickness. Such mixture is dry, poorly compacted and is more prone to segregation (flaking). On the other hand, asphalt mixture that contains excessive content of bitumen results in the weaker mixture of HMA due to high volumetric thickness of bitumen film. The rational use of bitumen is also important because bitumen is the most expensive component in the HMA mixture. The bitumen batcher does not always weigh bitumen portions precisely. Their mass deviations from the amount determined by JMF and its variation impair the HMA composition and performance (Bražiūnas, Sivilevičius 2010). Bitumen content in the HMA mixture is an important factor in determining the durability of the asphalt pavement. The dynamic (complex) modulus $\left|E^{*}\right|$ is one of the most important properties of the HMA, which influences the structural response of a flexible pavement. The $\left|\mathrm{E}^{*}\right|$ determines the ability of a material to resist compressive deformation as it is subjected to cyclic compressive loading (Li et al. 2012; Zeiada et al. 2014).

AMPs use various technological schemes to produce HMA mixtures of various structure and capacity (Mogaver et al. 2012). A batch-type AMP has become

Corresponding author: Justas Bražiūnas

E-mail: justas.braziunas@vgtu.lt 
the most popular (Sivilevičius, Šukevičius 2009). Modern AMPs are capable of producing higher-quality HMA mixtures compared to that established in the standards. Component amounts, which depend on errors of dosing or other technological processes, homogeneity of materials and actions of an operator, frequently deviate from JMF by amounts less than the permitted tolerances. Technical and technological parameters of an AMP enable us to state that statistical tolerances set in the standards may be tightened through a better use of AMP capabilities. It would enable us to use the achievements of the technological progress through the implementation of the developed and upgraded AMP (Bražiūnas, Sivilevičius 2011; Bražiūnas et al. 2013).

Bitumen temperature is the second technological parameter of the BBS. It influences physical, chemical, rheological and mechanical properties of the produced asphalt mixture. Bitumen may be rigid and friable at low temperature, liquid and fluid at high temperature and semi-rigid or rigid at medium temperature. Due to temperature fluctuations from -30 to $50{ }^{\circ} \mathrm{C}$, the dynamic modulus of bitumen changes as many as 37,000 times (Jenks et al. 2011). When asphalt mixture is produced using bitumen, which is too cool and, therefore, too viscous (consistent), it hardly turns into a thin film, which should coat all mineral particles with solid layers of appropriate thickness to make a strong compacted structure of the mixture. When too hot or overheated mineral aggregates are used, bitumen may burn: it degrades chemically, volatilizes, its colloidal composition changes and rheological properties deteriorate.

Oxidation of bitumen intensity mostly depends on temperature (De Moraes et al. 2010) as well as the duration and intensity of contact with oxygen, and thickness of bitumen film coating mineral fillers (Herrington 2012). Heating time and temperature have significant impact on rheological properties of bitumen, such as viscosity, complex modulus, and creep stiffness (Dessouky et al. 2011). Tran et al. (2010), Huh and Robertson (1996) evaluated the prediction models of bitumen's critical high temperature on the properties of the HMA mixture. Four chemical groups of bitumen (colloid fractions) are not clearly defined. Some overlap between the groups is possible. However, this does enable bitumen rheology to be set against broad chemical composition (Redelius 2009). Four generic fractions play an inconsistent role in the temperature susceptibility of bitumens and the correlation degree of each fraction is somewhat different. The existence of aromatics and asphaltenes can lower the sensitivity to temperature changes, whereas saturates and resins may have an adverse impact on the temperature susceptibility of bitumens. As for the correlation degrees, resins show the closest correlation with the temperature susceptibility of bitumens, then asphaltenes and aromatics, and the correlation between temperature susceptibility and saturates is relatively weak (Firoozifar et al. 2011; Liang et al. 2010). The physical properties of asphalt binder vary tremendously with temperature (Anderson 2011). Application of mathematical models for chemical composition enables us to identify viscoelastic properties of bitumen (Greenfield 2011).

Essentially, satisfactory performance of bitumen on a road can be ensured if four properties are controlled: rheology, cohesion, adhesion and durability. The rheological properties of bitumen at a particular temperature are determined by both the constitution (chemical composition) and structure (physical arrangement) of molecules in the material. Changes in the constitution or structure or both alter the rheology (Read, Whiteoak 2003).

Oxidation is the factor that mostly influences the shortterm ageing of bitumen, which is extremely harmful at low temperatures. When the contact area of bitumen with oxygen is large, this interaction lasts for a long time. Bitumen and oxygen reactions may occur during the process of HMA production. In such cases, bitumen characteristics irreversibly change, which worsens its penetration, softening point and friability temperature.

Just as many other organic substances, bitumen is affected by oxygen, ultraviolet radiation and changes in temperature (Zhang et al. 2011; Huang, Zeng 2007). These external influences can cause bitumen to harden, resulting in a decrease in penetration $\left(\mathrm{Pen}_{25}\right)$, an increase in softening point $\left(T_{s p}\right)$ and, usually, an increase in penetration index $\left(I_{p}\right)$. The most important mechanisms of bitumen hardening are: oxidation, volatilisation, steric or physical factors, and exudative hardening. Hardening due to oxidation has long been considered the main cause of ageing to the extent that other factors have been given scant consideration (Petersen, Glaser 2011). Polar groups containing oxygen are formed and these tend to associate into micelles of higher micellar weight thereby increasing the viscosity of bitumen (Read, Whiteoak 2003). Due to irreversible processes of oxidation, the aged bitumen stiffens and its physiochemical properties, ductility, adhesion and cohesion as well as sectional composition (relative amounts of asphaltenes, oils and resins) change. The flexible pavement used for roads usually consists of the HMA mixture, made in the central AMP including granules of RAP. The amount of the added reclaimed asphalt pavement depends on mineral materials and their homogeneity. Vislavičius and Sivilevičius (2013) presented the algorithm for predicting the composition of mineral constituent of recycled HMA, taking into consideration the variation of gradation of all mineral materials and reclaimed asphalt pavement, in the absence of random batching errors.

During the lifetime of pavements, asphalt binders experience various aging environments associated with variations in temperature and oxygen accessibility. Aging can significantly change the rheological properties of asphalt binders and cause asphalt hardening, leading to embrittlement and reduced life-span of pavements. Therefore, it is of substantial importance to have a good understanding of changes in rheology and structure of asphalt 
binders under aging environments (Qin et al. 2014). The observed rheological hardening is closely correlated and attributed to the compositional changes within asphalts upon field aging, which involves the conversion of aromatics into toluene soluble asphaltenes and an increase in the total pericondensed aromaticity and carbonyl and sulfoxide functional groups. Although rheology is significantly impacted by field aging, the temperature dependence of rheological properties remains unchanged at various aging severities. The Arrhenius temperature dependence is suggested to describe the viscoelasticity of unmodified binders rather than the Super-Arrhenius or Vogel-Fulcher-Tamman or Williams-Landell-Ferry equations due to a small dynamic fragility of 16 . There are a number of mathematical models for modelling rheological properties of bitumen (Yusoff et al. 2013). In recent investigations, the double-log model has been found to be the most accurate equation in describing the effect of temperature on the viscosity of bitumen over a wide range of temperature while the Barus model with the temperature-dependent parameter has been found to be the most appropriate correlation to represent the effect of pressure (Behzadfar, Hatzikiriakos 2014). Rimša et al. (2014) proposed the semi-analytical model for evaluation of the binary normal contact of spherical particles interacting via weaker multi-layered interface and investigated its applicability in modelling of asphalt mixtures.

At high temperatures associated with mixing and compaction of bituminous mixtures, most of the unmodified bitumens exhibit Newtonian behaviour and hence the rheological behaviour is characterised by Newtonian viscosity. This Newtonian viscosity is the most important factor that affects the mixing ability of aggregates with binder, and ease of compaction of the mix. It is also understood that with reducing temperature, bitumen exhibits viscoelastic non-Newtonian fluid characteristics. Anjan Kumar et al. (2014) developed a thermodynamically consistent, frame-invariant viscoelastic non-Newtonian fluid model to characterise the rheological properties of the binders tested in a rotational viscometer. The binders were subjected to steady and variable shear rate experiments in a rotational viscometer. The model developed was able to predict reasonably the response of the binders subjected to various protocols. In addition, bituminous mixtures were fabricated at different mixing and compaction temperatures using these binders, and the evolution of volumetric properties was investigated. The experimental investigation on mixtures showed that for identical aggregate gradation, the apparent viscosity of the binders played a critical role on the final volumetric properties obtained.

The analysis of current research works shows that scientists frequently investigate the variation of characteristics of bitumen as a binding material used without mineral aggregates as well as its performance in the asphalt layer of road pavement. Investigations focus on possibilities to apply new additives, which improve bitumen characteristics and inhibit its oxidation reactions. The aim of this paper is to present scientifically based improved technological parameters of the BBS of AMP, enabling to produce high quality HMA mixture.

\section{Modelling variation processes of bitumen characteristics in technological equipment}

Witczak (2005) conducted a theoretical investigation on short-term and long-term ageing prognoses of bitumen binder. Initial and specified mathematical models (regression equations) showed that bitumen temperature, viscosity and its effective content in the mixture, which depends on bitumen dosing errors, have an impact on HMA dynamic modulus $E$ (Shen et al. 2013; Witczak, Fonseca 1996). The increasing viscosity increases dynamic modulus $E$ during a short period; however, during a long period, road pavement asphalt starts to scale due to larger viscosity. An increase in effective bitumen content consistently reduces $E$ value. Air void content up to $3.5 \%$ has no impact; whereas at rates higher than $3.5 \%$, it reduces its dynamic modulus $E$. Affected by high temperature and oxidation processes in the equipment of AMP, bitumen changes its chemical and group composition irreversibly, which, in turn, worsens the structure, adhesion, cohesion and rheology of the binder in the asphalt layer of road pavement. Studies on the formation of carbonyl content in bitumen at high temperatures demonstrate that (Fig. 1) the amount of carbonyl $r_{C A}$ in organic binder varies. The formation of carbonyl compounds $r_{C A}$ rapidly increases under the temperature of bitumen binder ranging from $180-190{ }^{\circ} \mathrm{C}$ and higher.
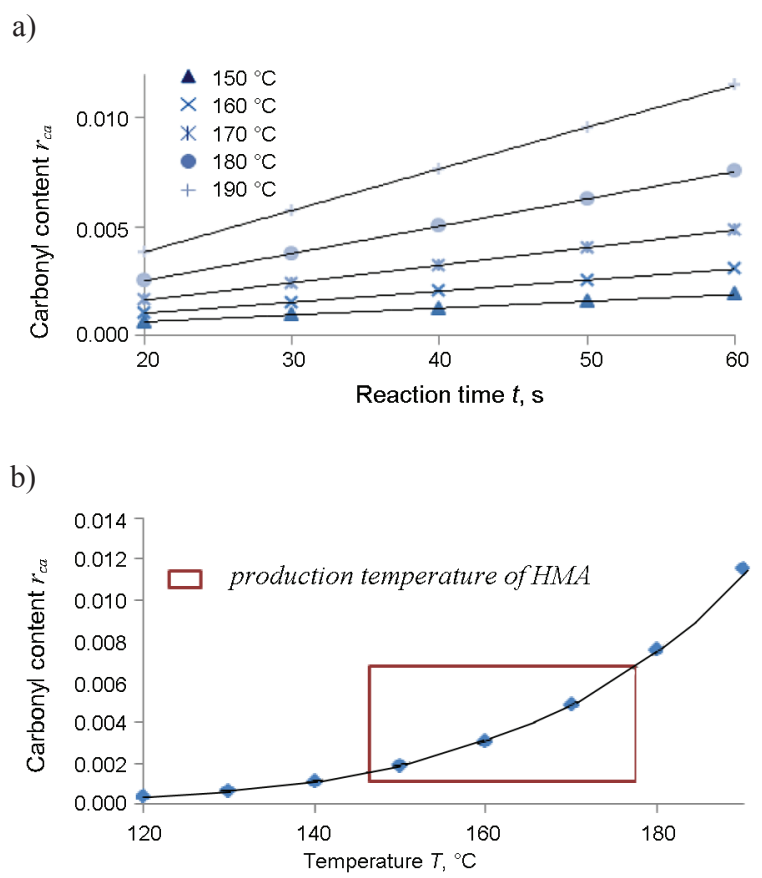

Fig. 1. Effect of temperature on carbonyl formation in bitumen during oxidation period of: $\mathrm{a}-20-60 \mathrm{~s}$ at $150-190{ }^{\circ} \mathrm{C}$ temperatures; $\mathrm{b}$ - in $1 \mathrm{~min}$ at different temperatures 


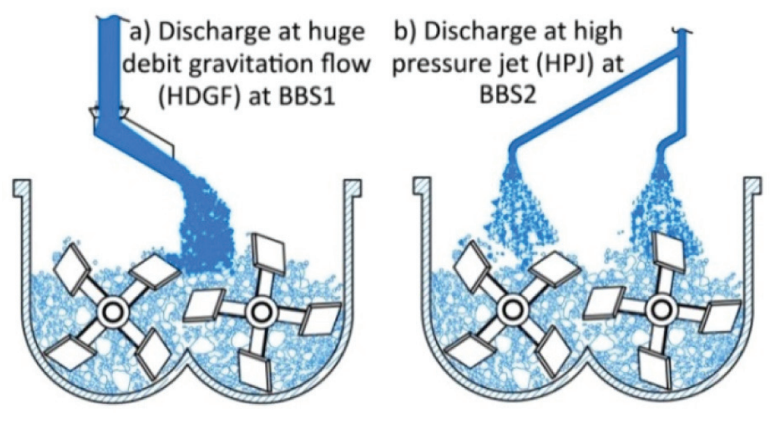

Fig. 2. Technologies of discharging weighed hot bitumen into a mixer in various bitumen batching systems (BBS1 of AMP1 and BBS2 of AMP2)

Two BBSs with different mixing methods of the batched bitumen were investigated (Fig. 2).

Due to differences in technical parameters and flow particular to BBSs (debit, pressure, jet characteristics), the batched bitumen binder is sprayed into the mixer in drops (high pressure jet) or is discharged by high gravitation flow.

To determine oxygen concentration $C_{\mathrm{O}_{2}}$ distribution at different depths of bitumen drop or flow (according to coordinate $x$ ), the mathematical model was constructed according to the main Eqn (1) (Han et al. 2013; Jin et al. 2013). The obtained result enables us to determine the scope of oxidation due to oxygen concentration $\mathrm{C}_{\mathrm{O}_{2}}$ :

$$
\left(\frac{\partial C_{O_{2}}}{\partial t}\right)=\left(\frac{\partial D}{\partial x}\right)\left(\frac{\partial C_{O_{2}}}{\partial x}\right)+D\left(\frac{\partial^{2} C_{O_{2}}}{\partial x^{2}}\right)-r_{O_{2}},
$$

where: $C_{O_{2}}$ - oxygen concentration; $r_{O_{2}}-$ oxygen consumption (absorption); $x$ - depth coordinate; $P$ - pressure; $D$ - diffusitivity which depends on the level where oxygen diffusion occurs:

$$
\left(\frac{\partial P}{\partial t}\right)=\left(\frac{\partial D}{\partial x}\right)\left(\frac{\partial P}{\partial x}\right)+D\left(\frac{\partial^{2} P}{\partial x^{2}}\right)-\left(\frac{c R T}{h}\right) \frac{r_{O_{2}}}{c},
$$

where: $c$ - coefficient, which depends on the material. The initial equation is expressed as follows:

$$
\frac{\partial P}{\partial t}-\frac{\partial D}{\partial x} \frac{\partial P}{\partial x}-D \frac{\partial^{2} P}{\partial x^{2}}+b(P)=0 .
$$

Depth $L$ under investigation (according to coordinate $x$ ) is divided into finite elements (FE) through the use of the first Hermite polynomials. Pressure in FE $e$ is calculated as follows:

$$
P_{e}(t, x)=\left[N\left(\psi=\frac{x}{L_{e}}\right)\right]\left\{q_{e}\right\},
$$

where: $[N(\psi)]$ - shape function matrix; $\left\{q_{e}\right\}-$ the unknown quantities of the FE; $L_{e}$ - length of the FE. The FE of two nods is used when the unknown vector equals to:

$$
\left\{q_{e}\right\}^{T}=\left[P_{1}, \frac{\partial P_{1}}{L_{e} \partial \psi}, p_{2}, \frac{\partial P_{2}}{L_{e} \partial \psi}\right]
$$

Having integrated diffusion and thermal conductivity equations, the following equation is obtained:

$$
\left[H_{k}\right]\left\{\Delta Y_{k}\right\}=\left\{R_{k}\right\}
$$

where: $\left\{\Delta Y_{k}\right\}^{T}=\left[\left\{\Delta q_{k}\right\}^{T},\left\{\Delta T_{k}\right\}^{T}\right] ;\left\{R_{k}\right\}$ - vector of the right sides; $\left[H_{k}\right]-$ matrix of coefficients.

The specified solution of equation system (6) equals to:

$$
\left\{Y_{t+\Delta t, k+1}\right\}=\left\{Y_{t+\Delta t, k}\right\}+\left\{\Delta Y_{k}\right\} .
$$

Having taken into consideration thermal properties and temperature of bitumen, the presented task enables us to determine the distribution of pressure in bitumen drop or flow while falling into a mixer by their depth and time. When pressure distribution in a drop is determined, $\mathrm{CO}_{2}$ distribution in the bitumen binder drop or flow under investigation may be determined from other dependences.

\section{Experimental investigation of purposive change of BBS technical and technological parameters of AMP}

An active experiment (Fig. 3) conducted under real conditions of HMA production showed that the method of bitumen discharge from the batcher as well as its temperature and time of mixing with hot mineral aggregate have an impact on the characteristics of bitumen binder in the produced mixture of stone mastic asphalt (SMA).

Bitumen storage tanks, from which binder is pumped through pipelines are the same in both asphalt mixing plants (AMP1 and AMP2). Therefore, the assumption is made that bitumen PMB 45/80-55, which was used for the production of experimental SMA mixtures, was pumped having the same properties in both bitumen batching systems (BBS1 and BBS2). During the production of SMA mixture of the same composition in AMP1 and AMP2, the mixing time was changed. SMA $11 \mathrm{~S}$ mixtures were mixed with bitumen for 20,30, 40, 50 and 60 seconds in a pugmill. SMA $11 \mathrm{~S}$ mark HMA mixture for both AMPs was produced according to the same JMF from the same materials (granite screenings $(0 / 2 \mathrm{~mm})$, three fraction granite crushed stone $(2 / 5 \mathrm{~mm} ; 5 / 8 \mathrm{~mm} ; 8 / 11 \mathrm{~mm})$, activated mineral powder, adhesion enhancing additive Iterlene and cellulose fibre additive $C P A$ ).

All samples, 5 from each AMP, were taken according to the standard and tested in a certified laboratory. Also, the assumption was made, that the method for taking mixture samples and sample testing in a laboratory were the same for all samples. Laboratory investigations showed that the composition of HMA mixture produced in AMP1 and AMP2 varied inconsiderably and did not exceed tolerances indicated in the JMF value (Table 1). 


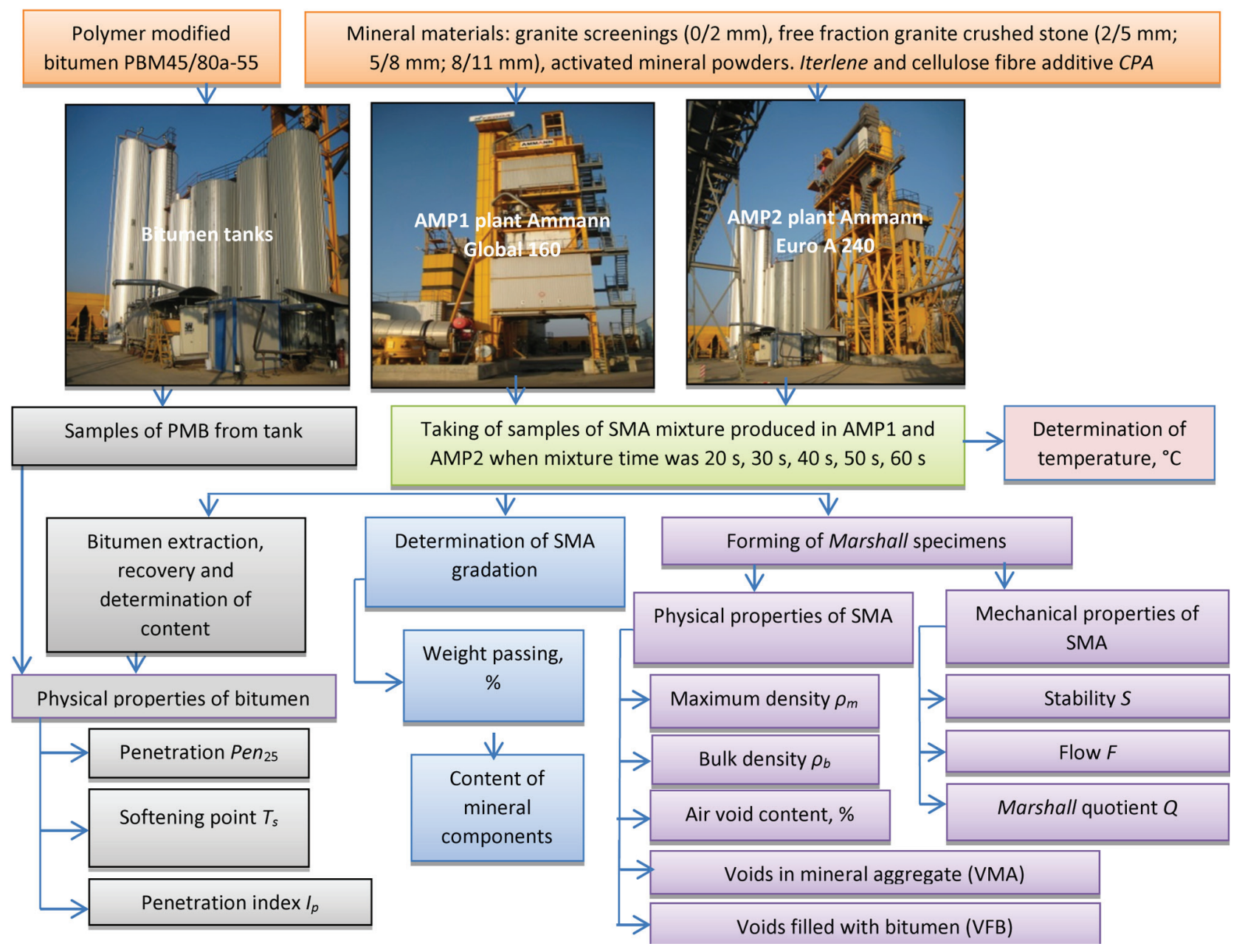

Fig. 3. Execution scheme of an active experiment conducted in an AMPs

Table 1. Composition of mineral part fraction of SMA mixture and its bitumen content

\begin{tabular}{|c|c|c|c|c|c|c|c|}
\hline & \multirow{2}{*}{ 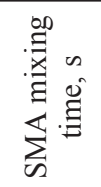 } & \multicolumn{5}{|c|}{ Fractions } & \multirow[b]{2}{*}{ 离 } \\
\hline & & $\stackrel{\infty}{\wedge}$ & $\begin{array}{l}0 \\
\ddot{\wedge}\end{array}$ & 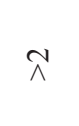 & \begin{tabular}{l}
\multirow{1}{1}{} \\
$\hat{6}$ \\
0 \\
0
\end{tabular} & $\begin{array}{l}\text { } \\
\stackrel{8}{0} \\
\dot{p}\end{array}$ & \\
\hline JMF & $20-60$ & 45.4 & 62.7 & 77.0 & 14.5 & 8.5 & 6.6 \\
\hline \multirow{5}{*}{$\bar{\sum}$} & 20 & 48.8 & 64.8 & 76.7 & 14.0 & 9.4 & 6.6 \\
\hline & 30 & 57.4 & 68.1 & 77.6 & 13.4 & 9.0 & 6.3 \\
\hline & 40 & 52.0 & 63.0 & 75.7 & 14.3 & 10.1 & 6.8 \\
\hline & 50 & 50.6 & 62.2 & 75.8 & 14.9 & 9.3 & 6.6 \\
\hline & 60 & 50.6 & 63.9 & 75.9 & 14.6 & 9.5 & 6.6 \\
\hline \multirow{5}{*}{$\sum_{\varepsilon}^{N}$} & 20 & 53.1 & 67.7 & 77.2 & 14.8 & 8.0 & 6.6 \\
\hline & 30 & 47.5 & 65.4 & 76.5 & 15.1 & 8.4 & 6.7 \\
\hline & 40 & 43.8 & 64.3 & 76.1 & 15.3 & 8.6 & 6.9 \\
\hline & 50 & 52.3 & 67.5 & 77.3 & 14.8 & 7.8 & 6.4 \\
\hline & 60 & 53.4 & 68.1 & 76.9 & 14.1 & 9.0 & 6.8 \\
\hline
\end{tabular}

Once weighed by different BBSs and discharged, bitumen was mixed in continuous two-valve AMP mixers of similar parameters from $20 \mathrm{~s}$ to $60 \mathrm{~s}$, the penetration of soluble bitumen extracted from SMA mixture samples and separated by rotating evaporator (Table 2) reduced from $49 \mathrm{dmm}$ to $39 \mathrm{dmm}$ (AMP1) and from $49 \mathrm{dmm}$ to $43 \mathrm{dmm}$ (AMP2), and its softening point increased from $55{ }^{\circ} \mathrm{C}$ to $59{ }^{\circ} \mathrm{C}$ (AMP1) and from $55{ }^{\circ} \mathrm{C}$ to $58{ }^{\circ} \mathrm{C}$ (AMP2).

It was also determined that mixing time has an impact on the physical and mechanical properties of SMA mixture (Fig. 4). When mixing time is increased from 20 to $60 \mathrm{~s}$, the air void content of SMA mixture produced in AMP1 and AMP2 decreased to $1.8-1.9 \%$. Marshall stability of the samples of the mixture produced in AMP1 increased from $7.5 \mathrm{kN}$ to $8.6 \mathrm{kN}$ when mixing time increased to $60 \mathrm{~s}$; in AMP2 - from $7.5 \mathrm{kN}$ to $8.5 \mathrm{kN}$. When mixing time of SMA mixture is increased, its flow tends to decrease. During the active experimental investigation carried out under real production conditions, it was identified that the technical and technological parameters of BBS impact on the properties of bitumen binder and produced HMA mixture. 
Table 2. Dependence of separated soluble bitumen properties of SMA mixture produced in AMP1 and AMP2 plants on mixing time and mixing temperature

\begin{tabular}{|c|c|c|c|c|c|}
\hline & 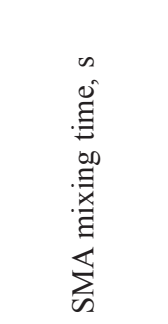 & 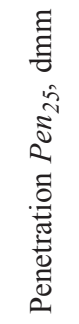 & 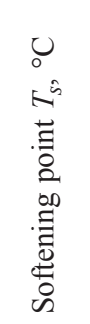 & 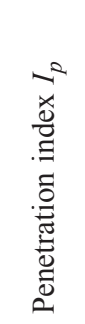 & 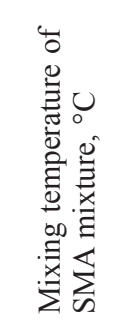 \\
\hline $\begin{array}{l}\text { Fresh } \\
\text { bitumen }\end{array}$ & $\begin{array}{c}0 \text { (before } \\
\text { production) }\end{array}$ & 48.7 & 54.98 & -0.1 & $150-180$ \\
\hline \multirow{5}{*}{$\begin{array}{l}\text { AMP1 } \\
\text { (BBS1) }\end{array}$} & 20 & 40 & 58.3 & 0.15 & 173.1 \\
\hline & 30 & 41 & 58.3 & 0.21 & 172.6 \\
\hline & 40 & 38 & 59.4 & 0.26 & 184.5 \\
\hline & 50 & 39 & 58.2 & 0.08 & 177.9 \\
\hline & 60 & 39 & 58.8 & 0.20 & 179.3 \\
\hline \multirow{5}{*}{$\begin{array}{l}\text { AMP2 } \\
(\mathrm{BBS} 2)\end{array}$} & 20 & 44 & 57.1 & 0.12 & 174 \\
\hline & 30 & 42 & 57.3 & 0.06 & 175.3 \\
\hline & 40 & 47 & 55.8 & 0.00 & 177.5 \\
\hline & 50 & 44 & 56.5 & -0.01 & 186.5 \\
\hline & 60 & 43 & 57.5 & 0.15 & 193.4 \\
\hline
\end{tabular}

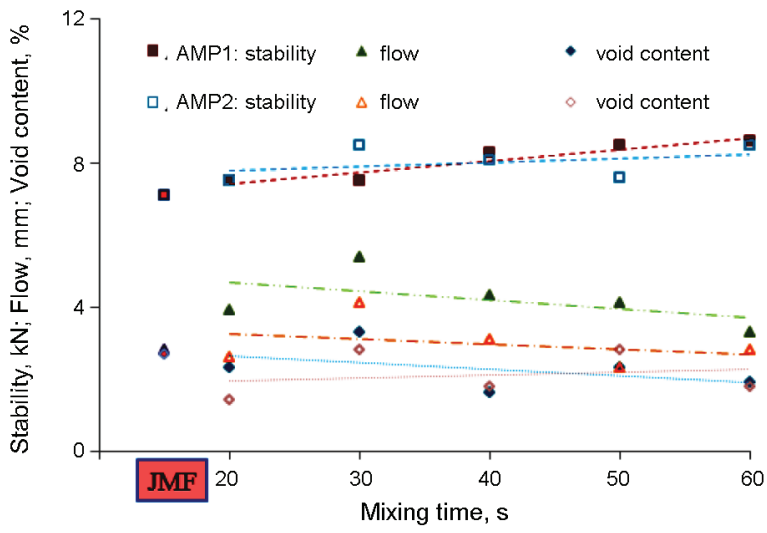

Fig. 4. Dependence of physical and mechanical properties of SMA mixture on mixing time of batches in an AMP

\section{Discussion}

No comprehensive investigation has been carried out on why and how bitumen characteristics change when AMP BBS of different structure and parameters are used in the technological process of HMA mixture production. Publications on the experiments conducted outside a laboratory but under real production conditions, especially with the data from active experiments conducted in AMP, are scarce. A large body of scientific publications is devoted to long-term ageing of bitumen binders in asphalt of road pavement. Even though its short-term ageing during the process of asphalt mixture production is much more important and significant, it has not been analysed sufficiently due to its complexity.

No comparison was made of theoretical or experimental studies demonstrating advantages and disadvantages of different systems of bitumen batching into the pugmill (discharge at huge debit gravitation flow - BBS1 and discharge at high pressure jet - BBS2) of a plant mixing batch type asphalt.

Considered as more appropriate by scientists and manufactures, the BBS2 has been used in practice for several decades. It allows bitumen, poured from a batcher tank, to be transformed into films that cover mineral aggregates. This forms small drops and jets of intermediate condition bitumen and reduces the time of asphalt mixing.

According to the investigation of oxidation rapidity (measured in quantity of carbonyl compounds) of bitumen when poured into a mixing plant, the oxidation be more intensive the bigger is the area of bitumen surface and thermal conductivity. Other factors which affect the intensity of oxidation are the time of contact between bitumen fragments and oxygen, high temperature and the size of drops or jets.

This article provides a mathematical model showing exercises of diffusion and conductivity which determines the air oxygen pressure distribution in the depth of bitumen film, $\mathrm{C}_{\mathrm{O}_{2}}$ concentration and the amount of carbonyls formed. The process of short-term ageing of bitumen varies due to oxidation when bitumen batch is discharged from the weighing bucket into a mixer by mass (Fig. 2) at concentrated high pressure flow (BBS1) and spraying it by high pressure in jets and drops (BBS2), due to different area of surface interacting with oxygen in ambient air. This process is speeded up by high temperature and increasing time of pitch of bitumen.

\section{Conclusions}

1. Variation of bitumen properties occurring due to oxidation depends on the technology of bitumen binder batching and discharging into a mixer. When bitumen is sprayed by high pressure jet (HPJ) and discharged by high debit gravitation flow (HDGF) into a mixer, its penetration decreases and softening point increases unevenly. The presented mathematical model enables us to determine the distribution of oxygen pressure in the course of time in a differently size bitumen drop falling into a mixer. It considers oxygen diffusion, which depends on temperature, and heat conductivity, which depends on temperature, density and specific heat.

2. The change in bitumen properties that occurs due to short-term oxidation ageing depends on the technology of bitumen batching and discharge into a mixer as well as the time of mixing all asphalt components. The active experiment conducted in an AMP with changed technological parameters demonstrated that once bitumen is batched and mixed, its penetration index increases from -0.1 to $0.12-0.15$ when dis- 
charging it into a mixer by high pressure in drops, and up to $0.21-0.26$ when pouring it at intensive free (gravitational) turbulent flow. When overheated materials are used, the batching technology in no longer the most important factor for bitumen oxidation. It is rather the temperature of other batched mineral aggregates, which is too high.

3 . In case of the asphalt mixture type SMA $11 \mathrm{~S}$, the increase in mixing time from $20 \mathrm{~s}$ to $60 \mathrm{~s}$ improved its most important normative physical and mechanical parameters. This can be explained by accelerating oxidation of bitumen binder that results in increased viscosity. Besides, growing amounts of batched bitumen turn into continuous oriented films of required thickness coating even the finest particles. Asphalt mixture type SMA $11 \mathrm{~S}$ produced in both AMPs according to the same JMF had a decrease in air void content by $30-33 \%$, namely, from $2.7 \%$ (according to $\mathrm{JMF}$ ) to $1.6 \%$ in AMP1 and to $1.8 \%$ in AMP2. In test specimens produced in the AMP1, Marshall stability increased from $7.5 \mathrm{kN}$ to $8.6 \mathrm{kN}$ with mixing time increasing from $20 \mathrm{~s}$ to $60 \mathrm{~s}$. In case of test specimens produced in the AMP2, this increase was from $7.5 \mathrm{kN}$ to $8.5 \mathrm{kN}$. Density has a tendency to reduce with increasing mixing time: in the AMP1, this reduction was from $5.4 \mathrm{~mm}$ to $3.3 \mathrm{~mm}$; and in the AMP2, it was from $4.1 \mathrm{~mm}$ to $2.8 \mathrm{~mm}$. When the time of mixing of SMA mixture components was increased from $20 \mathrm{~s}$ to $60 \mathrm{~s}$, its quality only improved.

\section{References}

Anderson, R. M. 2011. The asphalt binder handbook, MS-26. $1^{\text {st }}$ ed. Lexington, KY: Asphalt Institute. 242 p.

Anjan Kumar, S.; Sarvanan, U.; Murali Krishnan, J.; Veeraragavan, A. 2014. Rheological characterisation of modified binders at mixing and compaction temperature, International Journal of Pavement Engineering 15(9): 767-785. http://dx.doi.org/10.1080/10298436.2013.851792

Behzadfar, E.; Hatzikiriakos, S. G. 2014. Rheology of bitumen: effects of temperature, pressure, $\mathrm{CO}_{2}$ concentration and shear rate, Fuel 116: 578-587. http://dx.doi.org/10.1016/j.fuel.2013.08.024

Bražiūnas, J.; Sivilevičius, H.; Virbickas, R. 2013. Dependences of SMA mixture and its bituminous binder properties on bitumen batching system, mixing time and temperature on asphalt on asphalt mixing plant, Journal of Civil Engineering and Management 19(6): 862-872. http://dx.doi.org/10.3846/13923730.2013.843587

Bražiūnas, J.; Sivilevičius, H. 2011. Statistical analysis of component content deviation from job-mix formula in hot mix asphalt, in $8^{\text {th }}$ International Conference of Environmental Engineering, 19-20 May 2011, Vilnius, Lithuania. Selected papers, Vol. 3. 1044-1050.

Bražiūnas, J.; Sivilevičius, H. 2010. The bitumen batching system's modernization and its effective analysis at the asphalt mixing plant, Transport 25(3): 325-335. http://dx.doi.org/10.3846/transport.2010.40

De Moraes, M. B.; Pereira, R. B.; Simão, R. A.; Leite, L. F. M. 2010. High temperature AFM study of CAP 30/45 pen grade bitumen, Journal of Microscopy 239(1): 46-53. http://dx.doi.org/10.1111/j.1365-2818.2009.03354.x
Dessouky, S.; Reyes, Ch.; Ilias, M.; Contreras, D.; Papagiannakis, A. T. 2011. Effect of pre-heating duration and temperature conditioning on the rheological properties of bitumen, Construction and Building Materials 25(6): 2785-2792. http://dx.doi.org/10.1016/j.conbuildmat.2010.12.058

Firoozifar, S. H.; Foroutan, S.; Foroutan, S. 2011. The effect of asphaltene on thermal properties of bitumen, Chemical Engineering Research and Design 89(10): 2044-2048. http://dx.doi.org/10.1016/j.cherd.2011.01.025

Greenfield, M. L. 2011. Molecular modelling and simulation of asphaltenes and bituminous materials, International Journal of Pavement Engineering 12(4): 325-341. http://dx.doi.org/10.1080/10298436.2011.575141

Han, R.; Jin, X.; Glover, C. J. 2013. Oxygen diffusivity in asphalts and mastics, Petroleum Science and Technology 31(15): 1563-1573. http://dx.doi.org/10.1080/10916466.2011.559506

Herrington, P. R. 2012. Diffusion and reaction of oxygen in bitumen films, Fuel 94: 86-92. http://dx.doi.org/10.1016/j.fuel.2011.12.021

Huang, S.-C.; Zeng, M. 2007. Characterization of aging effect on rheological properties of asphalt-filler systems, International Journal of Pavement Engineering 8(3): 213-223. http://dx.doi.org/10.1080/10298430601135477

Huh, J.-D.; Robertson, R. E. 1996. Modeling of oxidative aging behavior of asphalts from short-term, high-temperature data as a step toward prediction of pavement aging, Transportation Research Record 1535: 91-97.

http://dx.doi.org/10.3141/1535-12

Jenks, C. W.; Jencks, C. F.; Harrigan, E. T.; Adcock, M.; Delaney, E. P.; Freer, H. 2011. NCHRP Report 673: A manual for design of hot mix asphalt with commentary. Washington, D.C.: Transportation research board of the National academies. 283 p.

Jin, X.; Cui, Y.; Glover, C. J. 2013. Modeling asphalt oxidation in pavement with field validation, Petroleum Science and Technology 31(13): 1398-1405. http://dx.doi.org/10.1080/10916466.2012.665115

Judycki, J. 2010. Determination of equivalent axle load factors on the basis of fatigue criteria for flexible and semi-rigid pavements, Road Materials and Pavement Design 11(1): 187-202. http://dx.doi.org/10.1080/14680629.2010.9690266

Li, J.; Zofka, A.; Yut, I. 2012. Evaluation of dynamic modulus of typical asphalt mixtures in Northeast US Region, Road Materials and Pavement Design 13(2): 249-265. http://dx.doi.org/10.1080/14680629.2012.666641

Liang, Y.; Feng, Z.; Yu, J. 2010. Effect of chemical compositions on temperature susceptibility of bitumens, Journal of Wuhan University of Technology - Materials Science Edition 25(4): 669-673.

http://dx.doi.org/10.1007/s11595-040-0067-2

Mogaver, W. S.; Austerman, A. J.; Bonaquist, R. 2012. Determining the influence of plant type and production parameters on performance of plant-produced reclaimed asphalt pavement mixtures, Transportation Research Record 2268: 71-81. http://dx.doi.org/10.3141/2268-09

Petersen, J. C.; Glaser, R. 2011. Asphalt oxidation mechanisms and the role of oxidation products on age hardening revisited, Road Materials and Pavement Design 12(4): 795819. http://dx.doi.org/10.1080/14680629.2011.9713895

Qin, Q.; Schabron, J. F.; Boysen, R. B.; Farrar, M. J. 2014. Field aging effect on chemistry and rheology of asphalt binders and rheological predictions for field aging, Fuel 121(1): 86-94. http://dx.doi.org/10.1016/j.fuel.2013.12.040

Read, J.; Whiteoak, D. 2003. The shell bitumen handbook. $5^{\text {th }}$ ed. London: Thomas Telford Ltd. 464 p. 
Rimša, V.; Kačianauskas, R.; Sivilevičius, H. 2014. Numerical analysis of asphalt mixture and comparison with physical Marshall test, Journal of Civil Engineering and Management 20(4): 570-580. http://dx.doi.org/10.3846/13923730.2014.920413

Redelius, P. 2009. Asphaltenes in bitumen, what they are and what they are not, Road Materials and Pavement Design 10(sup1): 25-43. http://dx.doi.org/10.1080/14680629.2009.9690234

Shen, S.; Yu, H.; Willoughby, K. A.; DeVol, J. R.; Uhlmeyer, J. S. 2013. Local practice of assessing dynamic modulus properties for Washington State mixtures, Transportation Research Record 2373: 89-99. http://dx.doi.org/10.3141/2373-10

Sivilevičius, H.; Vansauskas, V. 2013. Research and evaluation of ruts in the asphalt pavement on Lithuanian highways, Journal of Civil Engineering and Management 19(5): 609-621. http://dx.doi.org/10.3846/13923730.2013.817481

Sivilevičius, H.; Šukevičius, Š. 2009. Manufacturing technologies and dynamics of hot-mix asphalt mixture production, Journal of Civil Engineering and Management 15(2): $169-179$.

http://dx.doi.org/10.3846/1392-3730.2009.15.169-179

Tran, N.; Taylor, A. J.; West, R. C.; Kvasnak, A.; Turner, P. 2010. Evaluation of predictive models for determination of binder critical high temperature from mixture properties, TRB $89^{\text {th }}$ Annual Meeting Compendium of Papers DVD. Washington, D.C.: Transportation research board of the National academies.
Vislavičius, K. Sivilevičius, H. 2013. Effect of reclaimed asphalt pavement gradation variation on the homogeneity of recycled hot-mix asphalt, Archives of Civil and Mechanical Engineering 13(3): 345-353. http://dx.doi.org/10.1016/j.acme.2013.03.003

Witczak, M. W.; Fonseca, O. A. 1996. Revised predictive model for dynamic (complex) modulus of asphalt mixtures, Transportation Research Record 1540: 15-23. http://dx.doi.org/10.3141/1540-03

Witczak, M. W. 2005. Simple performance tests: summary of recommended methods and database. NCHRP Report 547. Washington, D.C.: Transportation Research Board. 25 p.

Yusoff, N. I. Md.; Jakarni, F. M.; Nguyen, V. H.; Hainin, M. R.; Airey, G. D. 2013. Modelling the rheological properties of bituminous binders using mathematical equations, Construction and Building Materials (40): 174-188. http://dx.doi.org/10.1016/j.conbuildmat.2012.09.105

Zeiada, W. A.; Kaloush, K. E.; Underwood, B. S.; Mamlouk, M. E. 2014. Improved method of considering air void and asphalt content changes on long-term performance of asphalt concrete pavements, International Journal of Pavement Engineering 15(8): 718-730. http://dx.doi.org/10.1080/10298436.2013.857775

Zhang, H. L.; Yu, J. Y.; Xue, L. H.; Li, Z. C. 2011. Effect of montmorillonite organic modification on microstructures and ultraviolet aging properties of bitumen, Journal of Microscopy 244 (1): 85-92. http://dx.doi.org/10.1111/j.1365-2818.2011.03511.x

Justas BRAŽIŪNAS. Dr Assoc. Prof at the Department of Transport Technological Equipment of Vilnius Gediminas Technical University (VGTU), Lithuania. Research interests: technologies for production of hot-mix asphalt mixture, bitumen storage, heating, pumping, metering and batching systems of asphalt mixing plants, short-term ageing of bitumen. 